\title{
Estado de exceção e maioridade penal no Brasil pós- democrático
}

Luciana Fernandes e Hamilton Ferraz

\author{
Luciana Costa Fernandes \\ É graduada em direito pela UERJ, mestra pelo do Programa de Pós \\ Graduação em Direito pela mesma universidade e doutoranda em \\ direito pela PUC-Rio. \\ Email: lucianafernandesppa@gmail.com \\ Orcid: http://orcid.org/0000-0003-1364-7420
}

\section{Hamilton Gonçalves Ferraz}

Doutorando em Direito na PUC-Rio. Mestre em Direito Penal e Bacharel em Direito pela mesma universidade.

Email: ferraz.hamilton.hgf@hotmail.com

ORCID: http://orcid.org/0000-0002-0471-2529

\section{Resumo}

O trabalho pretende realizar uma leitura constitucional crítica sobre o debate da redução da maioridade penal em face do conceito de estado de exceção. Para tanto, será feita breve apresentação do conceito de "estado de exceção", proposto por Giorgio Agamben. Na sequência, o trabalho adentrará no debate da maioridade penal, tendo em vista o contexto pós-democrático em que o Brasil se insere, e as perspectivas de futuro que se vislumbram a partir dos resultados das eleições de 2018 para o Congresso Nacional e a Presidência da República.

\section{Palavras-chave}

Maioridade penal, Estado de exceção, Pós-democracia, Cláusulas Pétreas

\begin{abstract}
The paper aims to elaborate a critical constitutional reading on the debate of penal imputabilitity regarding the concept of "state of exception", proposed by Giorgio Agamben. In sequel, the imputability debate is, itself, analysed, concerning the brazilian postdemocratic context and the future perspectives that are expected by the 2018 elections for National Congress and Presidence.
\end{abstract}

\section{Keywords}

Penal imputability, State of exception, Post-democracy, Entrenchment clauses 


\section{Introdução}

O presente momento jurídico-político, imbuído pelos choques de forças geopolíticas, econômicas e institucionais em disputa, de uma ou outra forma, resultaram na emergência e recém-chegada ao poder das forças mais reacionárias, conservadoras e abertamente autoritárias que se tem notícia desde o regime militar no Brasil. Nesse contexto, a eleição de Jair Bolsonaro para a presidência tem se mostrado sintomática, de um lado, da escandalosa adesão a plataformas de governo atentatórias aos direitos das minorias; e, de outro, da retórica discursiva da salvaguarda da Constituição. Se, em outros tempos, essa conjunção soaria no mínimo paradoxal, o que se tem apresentado é um cenário de falácia democrática mobilizado para autorizar um corrente projeto de suspensões e anulações de garantias constitucionais.

Nesse contexto, é tarefa extremamente difícil investigar qualquer tema mais sensível a direitos e garantias fundamentais sem se cair em idealismos jusfilosóficos, ou discussões teóricas que não estabeleçam suficientes diálogos com as demandas por ordem vigentes. É o que ocorre com a Justiça Juvenil, este ramo que, na percepção de Alessandro Baratta, desde sua fundação, no final do século XIX, foi sempre a parte mais sensível de todo o sistema punitivo, a mais problemática e qualificante, o lugar onde sua mistificação doutrinária e ideológica e, ao mesmo tempo, o seu caráter seletivo e destrutivo alcançaram seu ponto mais alto (BARATTA, 2013, p. 25). E que, por isso mesmo, tem sido objeto de diferentes propostas alinhadas com o recrudescimento de plataformas conservadoras que começamos a descrever.

Considerando a complexidade do contexto, este artigo se propõe, através de revisão bibliográfica, a apontar as perspectivas que se desenham para a maioridade penal no Brasil. Buscamos compreender a questão a partir de duas perguntas fundamentais: é possível a convivência entre regime totalitário e de exceção com a manutenção da famigerada "ordem constitucional"? Como o status de cláusula pétrea pode ser mobilizado politicamente para possíveis alterações na responsabilização de jovens que reflitam os totalitarismos instalados no Brasil?

Como referencial teórico fundamental para a presente análise, parte-se da categoria conceitual do estado de exceção, desenvolvido por Giorgio Agamben, e sua pertinência ao contexto político e social brasileiro contemporâneo. Na sequência, o debate da redução da maioridade penal será apresentado desde sua trajetória histórica nas legislações brasileiras e sua compreensão baseada na observância do Direito Internacional dos Direitos Humanos, até a indicação das principais propostas legislativas no tema para, após, desenvolver-se o argumento constitucional relativo à maioridade penal, percebendo-a como cláusula pétrea. Por fim, será feito breve quadro relativo ao momento político contemporâneo brasileiro e as perspectivas de futuro que se vislumbram em relação à idade de responsabilização penal em tempos de pós democracia, indicando se o status constitucional, tão reivindicado no campo teórico de produções do direito, de fato parece representar obstáculo para a ruptura com os direitos de pessoas jovens no Brasil, nos aparentes estados de exceção que anunciam os novos governos eleitos.

\section{Uma breve incursão ao "estado de exceção" constitucional em Giorgio Agamben}

Para uma conceituação inicial, Giorgi Agamben afirma ser o estado de exceção: 
O dispositivo original graças ao qual o direito se refere à vida e a inclui em si por meio de sua própria suspensão; a terra de ninguém, entre o direito público e o fato político, e entre a ordem jurídica e a vida (2004, p. 12).

Como leciona Edgardo Castro, Agamben frisa que a nomenclatura a que se refere é "estado de exceção", de maneira a afastar, desde logo, a ideia de "guerra" do conceito. Também conhecido como "estado de sítio", "martial law", "emergency powers", o estado de exceção é dispositivo nascido em tradições democráticas e constitucionais europeias do final do século XVIII e início do século XIX, e não revolucionárias. A ideia inicial era ser um mecanismo de salvaguarda institucional contra situações excepcionais de guerra e violência política, e passa a ser, a partir do século XX, uma prática habitual (CASTRO, 2016, p. 76-77), ou, nas palavras de Agamben, uma das práticas essenciais dos Estados contemporâneos, inclusive os chamados "democráticos", como paradigma de governo (AGAMBEN, 2004, p. 13).

Para construir a noção, o filósofo italiano se utiliza como pressupostos teóricos tanto as noções de biopoder/biopolítica, desenvolvidas por Michel Foucault, quanto o conceito de estado de exceção em Carl Schmitt.

O biopoder, na filosofia foucaultiana, representa uma forma peculiar de exercício de poder, emergente a partir da Época Clássica (metade do século XVIII na Europa Central), vinculada ao desenvolvimento do capitalismo industrial europeu, que inverteu a noção soberana de poder, "causar a morte ou deixar viver", para uma forma biopolítica, segundo a fórmula "causar a vida ou devolver à morte" (FOUCAULT, 1999, pp. 130-132). Trata-se de técnica que não exclui a disciplinar, mas que dela se utiliza; que não se dirigiria mais diretamente ao "homem-corpo", sim ao "homem-vivo", entendido enquanto "homem-

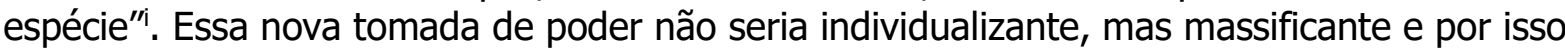
lida com a noção de populaçõesii, enquanto problema político e científico, "correlato de poder e como objeto de saber" (FOUCAULT, 2008, p. 103). Em aula transcrita no livro "Segurança, Território e Populações", o filósofo assenta que:

O público, noção capital do século XVIII, é a população considerada do ponto de vista das suas opiniões, das suas maneiras de fazer, dos seus comportamentos, dos seus hábitos, dos seus temores, dos seus preconceitos, das suas exigências, é aquilo sobre o que se age por meio da educação, das campanhas, dos convencimentos. (...) Da espécie ao público; temos aí todo um campo de novas realidades, novas realidades no sentido de que são, para os mecanismos de poder, os elementos pertinentes, o espaço pertinente no interior do qual e a propósito do qual se deve agir. (FOUCAULT, 2008, pp. 98-99)

O giro de realização das relações de poder fez emergir novas leituras das técnicas de governo, que deslocaram os sentidos de soberania - ou do "soberano" - porque não tão mais situadas no reino ou na figura central do imperium, mas em um conjunto que "se exerce, positivamente, sobre a vida, que empreende sua gestão, sua majoração, sua multiplicação, o exercício, sobre ela, de controles precisos e regulações de conjunto" (FOUCAULT, 1999, p.129). Aqui, não se destacaria o direito de causar a morte aos súditos, escatológico na imposição de penas capitais, mas o de "causar a vida ou devolver à morte" (FOUCAULT, 1999, p. 130). A gestão da espécie, assim, seria exercida em intervenções e controles reguladores em canais cada vez mais sutisiii. 
Foucault considera, ainda, a importância da atuação da norma enquanto instituidora dessas regulações e corretivos e comenta sobre as transformações, a nível constitucional, que o biopoder demanda:

"A instituição judiciária se integra cada vez mais num contínuo de aparelhos (médicos, administrativos etc.) cujas funções são sobretudo reguladoras. Uma sociedade normalizadora é o efeito histórico de uma tecnologia de poder centrada na vida. Por referência às sociedades que conhecemos até o século XVIII, nós entramos em uma fase de regressão jurídica; as Constituições escritas no mundo inteiro a partir da Revolução francesa, os códigos redigidos e reformulados, toda uma atividade legislativa permanente e ruidosa não devem iludir-nos: são formas que tornam aceitável um poder essencialmente normalizador." (FOUCAULT, 1999, pp. 135-136)

Isso quer dizer que o grupo de leis, de normas, a instituição jurídica e suas agências estariam cada vez mais aproximadas de seu caráter de norma - exatamente porque normalizadora. Tornar-se-ia cada vez mais latente a potência do sistema jurídico de dominar e gerir, de instituir o "poder sobre a população de fazer viver", de regulamentar. E esta nova configuração de poder também foi considerada por Agamben, segundo o qual o sentido biopolítico do estado de exceção estaria na "estrutura original em que o direito inclui em si o vivente por meio de sua própria suspensão" (AGAMBEN, 2004, p. 14). Daí o protagonismo do direito para a sustentação deste modelo de exceções.

O segundo pressuposto teórico fundamental para Agamben consiste na ideia de exceção formulada por Carl Schmitt em "A ditadura" (1921) e "Teologia política" (1922). De modo geral, Schmitt estava interessado em formular teorias para a noção de poder constituinte, que viria a ser identificado com a noção de decisãoiv - e, a partir daí, o titular deste poder (e, portanto, soberano) seria aquele pode decidir acerca do estado de exceção (entendido, por Schmitt, como a suspensão da norma); o soberano figura, ao mesmo tempo, dentro e fora da ordem jurídica (CASTRO, 2016, p. 79-80).

Agamben aproveita as ideias de Schmitt (2004, p. 53-57), mas refuta o seu argumento principal, qual seja, de que, paradoxalmente, o estado de exceção estaria dentro da ordem jurídica. Na verdade, a exceção não apenas está fora do direito (Idem, p. 54), como é o próprio mecanismo segundo o qual o direito inclui a vida, como visto em sua conceituação. Nas suas palavras:
(...)Mas igualmente falaciosas são as doutrinas que, como a de Schmitt, tentam inscrever indiretamente o estado de exceção num contexto jurídico, baseando-o na divisão entre normas de direito e normas de realização do direito, entre poder constituinte e poder constituído, entre norma e decisão. O estado de necessidade não é um "estado de direito", mas um espaço sem direito (mesmo não sendo um estado de natureza, mas se apresenta como a anomia que resulta da suspensão do direito) (idem, p. 79).

No Brasil, a categoria do estado de exceção, tal como cunhado por Agamben, popularizou-se consideravelmente no meio acadêmico, destacando-se abordagens bastante abrangentes e versáteis, que, em geral, se dedicam à questão criminal brasileira, relacionando a categoria conceitual ao sistema penal e ao cárcere, como formas de exceções permanentes (SOUZA, 2015, p. 226 e s.), bem como as práticas punitivas no campo da 
segurança pública (VALENTE, 2016; PEDRINHA, 2011, p. 181; CARVALHO, 2012, p. 101). De qualquer modo, é possível afirmar que a noção de estado de exceção vem adquirindo novas nuances, seja pelo acréscimo de novas contribuições ${ }^{\vee}$, seja através de críticas por outros ramos do saber atentas ao escravismo e racismo estrutural que marcam as nossas relações de podervi.

Alinhando-se a estas tentativas, é possível dizer que as leituras do estado de exceção agambiano refutam especialmente para a análise do contexto geopolítico vigente aquilo o que neste artigo ganha nuances próprias, que é a possibilidade da compatibilidade entre um regime de exceções e a ordem jurídica, cujo símbolo principal é a Constituição Federal. Segundo o autor, "o aporte específico da teoria schmittiana é exatamente o de tornar possível tal articulação entre o estado de exceção e a ordem jurídica." (AGAMBEN, 2004, p. 54). Seria, portanto, possível imaginar um estado de exceções constitucional? Ou aos totalitarismos seria imanente a necessidade da suspensão do conjunto normativo?

\title{
2.1. Ditadura comissária e a manutenção da ordem constitucional: delineamentos conceituais
}

Embora aparentemente um regime totalitário seja imediatamente imaginado como aquele em que há a revogação da velha constituição e imposição de uma nova ordem jurídica, Agamben destaca tratar-se de apenas uma das possibilidades - realização daquilo o que na construção schmittiana é referido enquanto "ditadura soberana" (2004a, p. 58). Marcado pela instauração do poder Constituinte, a imagem do absoluto rompimento com a ordem anterior se apresenta com uma tal escatologia que diminui as demais aparições do regime de suspensão das bases democráticas.

Não obstante, é na chamada ditadura comissária que sua construção ganha ainda maior destaque. Neste estado, segundo o autor, há a suspensão - e não revogação - da constituição

\begin{abstract}
'(...) para defender sua existência, tendo a função de criar as condições que permitam a aplicação do direito. Nela, a constituição pode ser suspensa quanto à sua aplicação "sem, no entanto, deixar de permanecer em vigor, porque a suspensão significa unicamente uma exceção concreta.". No plano da teoria, a ditadura comissária se deixa, assim, subsumir integralmente pela distinção entre a norma e as regras técnico-práticas que presidem sua realização.' (idem, p. 55)
\end{abstract}

Isso quer dizer que a relação entre o estado de exceção e a ordem jurídica é de pertencimento e não absoluta contradição. Ou seja, trata-se de uma técnica de governo que se apresenta legitimada pela manutenção do estado de definições próprias ao direito já instalado, mas cuja realização se manifesta na inerente capacidade de fazer suspender a realização de algumas das suas previsões mais basilares. Há uma tensão latente entre a existência e a aplicação de garantias, já que a "ditadura comissária mostra que o momento da aplicação é autônomo em relação à norma enquanto tal" (AGAMBEN, 2004, p. 58).

Interessa notar que a apresentação da suposta manutenção do ordenamento cumpre a função de sofisticar o regime de violações que é próprio às várias formas de aparição do estado de exceção. Assim, na ditadura soberana, é convocada a instalação de uma ordem jurídica, posterior, e que subsidia a atuação do soberano inteiramente. A cena é a de uma figura central que literalmente rompe com o documento de direitos básicos anterior e a ele incompatível.

Não é essa, contudo, a composição da ditadura comissária, em que a decisão pela aplicação ou não de um direito, por conveniência, torna muito menos visível o caráter 
totalitário de governo. Sem embargo, é igualmente possível dizer tratar-se de um regime marcado pela "eliminação física não só dos adversários políticos, mas também de categorias inteiras de cidadãos que, por qualquer razão, pareçam não integráveis ao sistema político" (idem, p. 13), característica fundamental do estado de exceção para Agamben.

A validade da norma jurídica, na leitura agambiana, é condição para a realização da exceção soberana. O sentido de autoridade estatal é garantido através da vigência do direito e do respaldo que o discurso, sem fundo material, em favor da democracia, confere aos soberanos. Isso quer dizer que a mera manutenção de uma Constituição não ilide por si a realização de um estado de exceção. Inclusive, é o vigor da ordem normativa que, contendo em si a possibilidade da sua suspensão, formula a sua relação essencial com a exterioridade - marca desta técnica de governo. Essa latência é descrita pelo autor: "O particular "vigor" da lei consiste nessa capacidade de manter-se em relação com uma exterioridade. Chamemos relação de exceção a esta forma extrema da relação que inclui alguma coisa unicamente através de sua exclusão" (AGAMBEN, 2007).

Assim, é possível dizer que a exceção e exclusão têm sido travestidas pela ordem de um discurso que, sob a falácia do respeito às normas, se mantém e estabiliza. A afirmação vaga da vigência da Constituição, por si, tem assumido o condão de relativizar o fundo totalitário das propostas que começam a se concretizar e que, em essência, representam a autoridade estatal que articula nova roupagem a velhas manobras tirânicas maquiadas de Estado Democrático de Direito. E que, como se verá, têm assumido também as vicissitudes demandadas no governo de populações, mais especificamente de certos jovens.

\subsection{Estado de exceção, cláusulas pétreas e poder constituinte derivado: por uma leitura crítica}

No Brasil contemporâneo, como o autoritarismo e os ataques à democracia advém do próprio regime eleito, sem que qualquer instituição seja formalmente alterada, para direitos fundamentais estarem sendo violados não se mostra mais necessária uma refundação constitucional completa, uma nova constituinte, ou se outorgar uma Constituição - que é símbolo fundamental do Estado democrático de direitos. O plano de fundo desse cenário refere-se às fissuras democráticas que vivemos em nível global, naquilo que se tem referido nas ciências políticas como "pós-democracia neoliberal" e que será explorado em item próprio deste artigo. Por ora, importa dizer que propor uma relação entre Estado de Exceção e cláusulas pétreas constitucionais vii não é tarefa simples, a começar pelo fato de que o primeiro não é, por si só, causa para a violação das segundas, cuja ruptura não depende, tampouco, de se estar no primeiro. Mas a sua valoração, para fins desse trabalho, precisa ser dialógica com o contexto apresentado.

O Estado de Exceção, por ser constituído essencialmente como uma situação de suspensão da norma por pretensas razões de crise, parece catalisar e tornar mais viável a violação de cláusulas pétreas constitucionais pelo poder constituinte derivado, que, imerso em supostos argumentos de "necessidade" e "urgência" - muito fomentadas, vale notar, por atores políticos relevantes, como a mídia e os meios de comunicação -, encontra menos freios, resistências e autocontenções para ruptura constitucional.

Ocorre que a violação de uma cláusula pétrea consiste, essencialmente, em atingir o núcleo essencial de uma Constituição, quebrando, ou fissurando a constituição originalviii, abrindo espaço para a visualização de uma nova Constituição, de ordem real ou material, que ocupa seu lugar, na forma de medida de exceção permanente. Esse é o risco que corremos no debate brasileiro envolvendo a consideração, ou não, da maioridade penal como cláusula pétrea. De um ou outro lado, persiste o estado de exceção, configurando 
ditadura soberana ou ditadura comissária. Mas, no primeiro caso, sem dúvida, há que se alterar a retórica democrática - limite que ainda não se sabe se estão os atuais conservadorismos dispostos a admitir.

Se a conjuntura apresentada está ou não aparelhada para tal retrocesso, ainda não se sabe. É anterior, porém, a esta análise a discussão do estado não só constitucional, como de cláusula pétrea, da temática, bem como as pautas que efetivamente tramitam nesta linha redutora de direitos. A emergência do tema nos convoca a revisitar os conservadorismos de tempos passados, matizados com o cenário presente e ainda decisões em nível internacional sobre a temática. 1

\section{A controvérsia constitucional da idade de responsabilização penal}

Há atualmente três Propostas de Emenda Constitucional de maior relevância, com o objetivo de reduzir a maioridade penal e que se encontram na Comissão de Constituição, Justiça e Cidadania: PEC 04/2019; PEC 115/2015 com origem na PEC 171/1993 e a PEC 21/2013.

A PEC 04/2019 foi aprovada logo no primeiro mês do atual mandato presidencial e aparece como uma resposta às tensões democráticas e demandas por recrudescimento à punição às custas da violação a direitos de minorias já abordada. Com a proposta de tornar penalmente imputáveis pessoas com mais de dezesseis anos, sem fazer ressalvas quanto aos crimes praticados nem estabelecimentos a que as penas devem ser cumpridas, o texto de justificativa torna explicito que se trata de uma arquitetura do populismo penal na era de um regime de exceção:
As eleições gerais de 2018 mostraram que a população brasileira exige do parlamento nacional o endurecimento das leis do código penal e da execução penal. Sabe-se que a principal função do Estado em uma nação democrática é garantir o respeito e a execução da Lei para todos. Nada é mais prioritário, hoje no Brasil que tomar as medidas necessárias para barrar o avanço da criminalidade $e$ responsabilizar os criminosos por seus crimes. ${ }^{\text {ix }}$

A PEC 115/2015 tem redação idêntica à PEC 171/93 e, reduz a maioridade penal para casos de crimes hediondos, homicídio doloso e lesão corporal seguida de morte, observando o cumprimento de pena em estabelecimento separado dos maiores de dezoito anos e dos menores de idade inimputáveis; a PEC determina ainda que a União, os Estados e o Distrito Federal criarão referidos os estabelecimentos ${ }^{\mathrm{x}}$.

Por sua vez, a PEC 21/2013 não traz ressalvas quanto aos crimes, como a primeira, mas reduz ainda mais o valor da imputabilidade, tornando penalmente responsáveis os maiores de quinze anos. Na fundamentação, que se apresenta de forma bastante opinativa, invocam-se argumentos como "evolução da sociedade" e "direito comparado" para se dizer que a "ciência psiquiátrica" comprova estarem esses jovens com "compreensão cada vez mais precoce da vida"xi.

Ressalte-se que, pelas principais pesquisas de opinião do país, são propostas que contam com forte aprovação popular (em torno de 80 a $90 \%$ da população) xii , além de conquistarem apoio evidente da grande mídia; porém, sofrem forte rejeição do meio acadêmico e especializadoxiii. 
Se Luciana Ballestrin diagnosticava, em outubro de 2017, que o Brasil vivenciaria "um período de transição política que caminha para o fechamento parcial de seu regime democrático" (2017, p. 17), o cenário desenhado ao final das eleições de 2018 se mostra ainda mais preocupante. Não apenas foi eleito, para a Presidência, o candidato com projeto mais reacionário, conservador e abertamente antidemocrático, como a composição do Congresso Nacional tende a lhe ser favorável (considerando eventual inclinação de partidos de centro para seus projetos de poder) e, ainda, sagraram-se vencedores nos Estados projetos de direita radical, como no Rio de Janeiro e São Paulo, os quais já demonstram apoio ao novo presidente.

Até hoje, na história política brasileira, nenhum candidato à presidência se mostrou tão simpático ou favorável à redução da maioridade penal como Jair Bolsonaro, que definiu sua posição explicitamente em seu programa de governo. Seu Ministro da Justiça e Segurança Pública, ex-juiz federal Sérgio Moro se alinha ao novo presidente, e defende, também a redução da maioridade para crimes hediondos e equiparados ${ }^{\text {xiv }}$. Não é por outro motivo que a PEC 04/2019 tem como um dos redatores um de seus filhos, o senador Flávio Bolsonaro (PSL/RJ).

É verdade que, como demonstrado acima, as PEC's que buscam reduzir a maioridade penal são praticamente contemporâneas (e paradoxais) ao nascimento da Constituição de 1988. Contudo, sempre encontraram resistência considerável no Congresso, sendo muitas vezes arquivadas e desarquivadas em diversas comissões conforme o momento eleitoral mais ou menos propício. Hoje, porém, o risco de redução da idade de responsabilização penal no Brasil nunca foi tão grande e real. Mas o que isto atinge, em nível constitucional e de proteção internacional de direitos humanos?

\section{1. trajetória da maioridade penal como cláusula pétrea}

Embora em tempos de exceção, como propomos neste trabalho, o status constitucional de uma cláusula pétrea não ilida por si a suspensão de direitos, é possível dizer que este status tende a alterar a retórica de legitimação. Assim, ainda se sustenta a discussão sobre se a idade para responsabilização de jovens pode ser alterada sem que se macule o núcleo central da constituição. Ou seja, de modo a entender como a pauta altera a legitimação democrática dos totalitarismos vigentes.

Até se chegar ao atual artigo 228 da Constituição de 1988, é necessário, primeiramente, compreendermos, de forma breve, o desenvolvimento legislativo brasileiro na matéria.

Nas Ordenações Filipinas de 1603, no Livro V, Título CXXXV previa-se certa diferenciação em termos de pena para menores de 17 anos, e os entre 17 e 20 anos (SHECAIRA, 2015, p. 28). No Código Criminal do Império (1830) os menores de 14 anos eram inimputáveis (art. 10), porém, caso se demonstrasse seu discernimento, seriam imputáveis e recolhidos a Casas de Correção (art. 13); os maiores de 14 e menores de 17 contavam com penas mais brandas (arts. 34 e 35) e os maiores de 17 e menores de 21, a seu turno, recebiam atenuação na pena em razão da idade (art. 18, item 10). Não apenas as Casas de Correção mal saíram do papel (Idem, p. 30), como se convivia com a chamada "roda dos expostos", sistema que chegou ao Brasil por volta do século XVIII e que, destinado ao acolhimento de crianças abandonadas pelos pais, representava na prática um grande infanticídio, com enormes índices de mortalidade infantil (DEL PRIORE, 1991, p. 98; SPOSATO, 2006, p. 27). 
Na República Velha, sob a égide do Código Penal de 1890, a imputabilidade penal foi reduzida para 9 anos de idade (art. 27, $\S 1^{\circ}$ ); entre 9 e 14 anos a imputabilidade ficava condicionada à presença do discernimento, determinando-se o recolhimento a estabelecimentos disciplinares industriais pelo tempo que o juiz achasse conveniente, desde que não ultrapassasse 17 anos (art. 27, §2 c/c art. 30); entre 14 e 17 anos, o código previa uma pena mais branda (art. 65), podendo já os maiores de 14 serem recolhidos a estabelecimentos industriais até os 21 anos (art. 399, §20); e os maiores de 17 e menores de 21 faziam jus a uma atenuante (art. 65, §11). Esse era um sistema que, na sagaz observação de Nilo Batista, tornava possível a internação de uma pessoa dos 9 aos seus 21 anos. Assim como as Casas de Correção, os estabelecimentos industriais também não saíram do papel, embora o tratamento tenha se especializado de forma tímida e precária no período, ensaiando-se o encaminhamento desses jovens a institutos e estabelecimentos diferenciados (BATISTA, 1990, p. 39-43).

Em 1921, a Lei 4.242 deu novo tratamento à imputabilidade penal, elevando a idade de responsabilização para 14 anos, submetendo o maior de 14 e menor de 18 anos a processo especial, não penal, e eliminando de uma vez o critério do discernimento, alcunhado de "adivinhação psicológica" por Evaristo de Moraes (1927, p. 122) e, antes, criticado acidamente por Tobias Barreto (1926, p. 16-17). De se espantar que, passado quase um século desta discussão, volta-se a exumar este critério da tumba jurídico-penal nas mãos de um ou outro parlamentar comprometido com a eterna sede de segurança e tranquilidades públicas, nunca plenamente saciadas, mas sempre politicamente úteis.

Em 1927, de modo a dar tratamento específico aos jovens entre 14 e 18 anos, promulga-se o nosso primeiro Código de Menores, que deve seu nascimento a todo um movimento de críticas cada vez mais severas, não apenas quanto à mistura entre jovens e adultos, às insuficiências e ilegalidades dos estabelecimentos existentes, mas passando pela própria ideia de punição e repressão a crianças e adolescentes por meio do aprisionamento (RIZZINI, 2005, p. 17). Esse é um momento crucial no caminho da responsabilização de jovens, porque se passa de um estado de pouca diferenciação em geral para a chamada doutrina menorista, em que o limite de idade acompanha diferenciações na forma como responderiam por atos em conflito com a lei tendenciosas a construir todo um aparato que os transformou em meros objetos de tutela.

Posteriormente, promulga-se o Código Penal de 1940, que mantém o limite etário em 18 anos, o que foi mantido até hoje. Em relação ao artigo 228 da Constituição de $1988^{\mathrm{xv}}$, este surge em um peculiar momento de nossa história penal-juvenil, em que, com muita luta e intensa mobilização nacional e internacional, se consegue superar os paradigmas vigentes à época, quais sejam, o menorismo e a doutrina da situação irregular, que já vinham desde o referido Código de Menores de 1927 e reforçados com o Código de 1979 - que, por desconhecerem o adolescente como sujeito de direitos, permitiam toda sorte de abusos e violações de direitos fundamentais (RIZZINI, PILOTTI, 2011, p. 307-320; DEL PRIORE, 2013, p. 364-365).

\section{É precisa a análise de Vera Malaguti Batista quando conclui que}

o Código de Menores fortalece a figura do juiz e não faz menção a nenhum direito da criança. Nos processos relativos a adolescentes infratores não existe a figura da defesa do acusado. O jovem em "situação irregular" é processado e entra no circuito penal sem que apareça a figura de advogado (BATISTA, 1998, p. 70). 
Ainda a respeito do menorismo e da doutrina da situação irregular, convém destacar a lição de Carvalho, Fernandes e Mayer:
Ao concluir que determinada parcela da juventude brasileira (parcela, de regra, pobre e com acesso precário a bens básicos como saúde, moradia e educação) estaria em "situação irregular", o Estado delegava a si mesmo o poder de atuar coercitivamente sobre essa população vulnerável, impondo diversas medidas de caráter punitivo, dentre as quais o sequestro involuntário em instituições de recolhimento. Assim, a punição de "menores" (e de suas famílias) consistia na "solução" particularizada de problemas cujas origens eram majoritariamente estruturais. E, como resposta à pobreza, à miséria e à exclusão social, a única alternativa oferecida pelo Estado é a segregação marginalizadora das crianças e dos adolescentes rotulados como "irregulares". Desse modo, o poder público eximia-se da responsabilidade de desenvolver políticas públicas que garantissem direitos e, ao invés de inclúi-los socialmente, produzia o aumento da exclusão por meio do recolhimento coercitivo (CARVALHO, FERNANDES e MAYER, 2012, p. 20).

A partir dos anos 80 , no contexto da redemocratização e abertura política, um forte movimento em favor da infância e juventude no país (o que já acontecia internacionalmente), questionou os paradigmas e métodos empregados até então para tratar esta classe de pessoas. Formou-se o Movimento Nacional de Meninos e Meninas de Rua, que chegou a contar com o apoio do Fundo das Nações Unidas para a Infância (UNICEF); constatou-se a falência do modelo da FUNABEM e construiu-se forte oposição à doutrina da situação irregular, conseguindo-se concretizar na Constituição as concepções fundamentais da Convenção Internacional dos Direitos da Criança, conquista da Frente Nacional de Defesa dos Direitos da Criança e da campanha "Criança Constituinte" lançada pela UNICEF (OLIVEIRA, ROMÃO, 2015, p. 26-27).

O movimento de superação do status quo anterior se edifica na chamada doutrina da proteção integral que se materializa em nossa Carta, nos dispositivos protetivos da infância e juventude (arts. 227 a 229), bem como no nascimento do ECA, em 1990. Estes dois textos passam a tratar a criança e o adolescente como sujeitos, garantindo-Ihes seus direitos fundamentais e sua responsabilização diferenciada.

Na lição de Karyna Sposato (2006, p. 61), a doutrina da proteção integral seria ilustrada por seis aspectos principais: reconhecimento de crianças e adolescentes como sujeitos de direitos; institucionalização da participação comunitária pelos Conselhos de Direitos; hierarquização da função judicial, com transferência de competência aos Conselhos Tutelares para agir diante da ameaça ou violação de direitos da criança no âmbito municipal; municipalização da política de atendimento; eliminação de internações não vinculadas ao cometimento de delitos ou contravenções; incorporação explícita de princípios constitucionais em casos de infração penal, prevendo-se a presença obrigatória de advogado e do Ministério Público na função de controle e contrapeso. Destaca-se ainda a impossibilidade absoluta de internação conjunta de adolescentes com adultos (art. 185, ECA).

Foi neste sentido que caminhava o tratamento juvenil internacional, o que veio a se consolidar, dentre outros documentos, na importantíssima Convenção sobre os Direitos da Criança (tratado com mais rápida e ampla aceitação de toda a história), assinada e ratificada pelo Brasil em 1990. E é nesse contexto que se assentou em nossa Constituição a imputabilidade penal aos 18 anos, no art. 228 (na mesma linha da anterior Reforma Penal de 1984, que justifica a idade penal em 18 anos no item 23 de sua Exposição de Motivos) xvi. 
Para além da referida Convenção internacional, a jurisprudência da Corte Interamericana que Ihe dá concretude no seio do Sistema Regional de Proteção a Direitos Humanos, do qual o Brasil faz parte, tanto por ter ratificado a Convenção Americana Sobre Direitos Humanos, como por aceitar a Jurisdição da Corte IDH.

A Corte IDH, ao longo dos anos 90 e 2000 construiu um verdadeiro modelo interamericano de justiça juvenil, baseado no seguinte grupo de casos xvii: Villagrán Morales vs Guatemala (1999); Opinião Consultiva 17/02; Instituto de Reeducação do menor vs Paraguai (2004); Bulacio vs Argentina, 2003; Mendoza e outros vs Argentina, 2013. Dentre estes, nos interessa particularmente a OC 17/02 e o caso Mendoza.

A OC 17/02 a consolida, no âmbito da jurisprudência da Corte IDH, os principais vetores da doutrina da proteção integral, estabelecendo o respeito a direitos humanos de crianças em cinco pontos: (i) definição de criança (toda pessoa menor de 18 anos); (ii) igualdade material; (iii) interesse superior da criança; (iv) deveres da família, sociedade e Estado para com crianças; ( $v$ ) procedimentos judiciais ou administrativos em que participem crianças, em estrita observância das garantias oriundas do devido processo legal.

No caso Mendoza e outros vs Argentina, o que nos interessa são os parâmetros formulados pela Corte para se verificar se uma sanção penal juvenil é ou não convencional: a) "ultima ratio" e máxima brevidade, no maior sentido restritivo possível; b) delimitação temporal desde o momento de sua imposição, proibindo-se a aplicação de penas privativas de liberdade com duração indeterminada ou que redundem na privação de dito direito de forma absoluta; c) revisão periódica das medidas de privação de liberdade de menores de idade e d) obediência ao princípio do interesse superior da criança e a máxima satisfação de seus direitos, tendo por finalidade sua reintegração social.

A partir deste panorama, a maioridade penal deve ser lida também de um ponto de vista material, conforme a garantia de direitos humanos e fundamentais, mais especificamente, o direito de crianças e adolescentes à integridade psicofísica e ao desenvolvimento da personalidade, drasticamente comprometidos a partir da sujeição destas pessoas ao sistema penal adulto, uma vez que, já no âmbito do direito interno, a Constituição considera os menores de 18 anos como pessoas em condição peculiar de desenvolvimento (art. 227, §30, v). Dado o tratamento diferenciado e o resguardo que a Constituição assegura a esses sujeitos de direito, imputabilidade é definida também de acordo com o grau de desenvolvimento do jovem e a formação de sua personalidade, e como apenas em certa faixa etária sua personalidade encontra-se devidamente formada para suportar eventual punição penal, minimizando-se o risco de reincidência. Até mesmo por interpretação sistemática se percebe como a inimputabilidade, por estar inserida no âmbito da consagração de direitos, já simboliza sua importância para os propósitos constitucionais. Entender a questão de outra forma traz o risco de se esvaziar a garantia, já que faria pouca ou nenhuma diferença se reduzir a idade para catorze, doze ou dez anos.

Por isso, essa inimputabilidade do adolescente autor de ato infracional é cláusula pétrea pelas seguintes razões (que não excluem outras): (i) a doutrina da proteção integral impõe que essa inimputabilidade seja lida não como mera incapacidade de culpabilidade, mas como defesa ao direito individual de desenvolvimento da personalidade do jovem, o que seria violado com a redução; (ii) pensando em proporcionalidade como vedação ao excesso e proibição da proteção deficiente, salta aos olhos que essa medida é desproporcional, afrontando também a jurisprudência da Corte IDH. O Estado, ao ponderar a defesa de bens jurídicos, a proteção da sociedade em relação aos direitos individuais do jovem, claramente prejudica a este de forma excessiva; (iii) à luz de nossa história penal juvenil e do quadro 
empírico atual do sistema penal de adultos e juvenil, marcados pela superlotação e violações sistemáticas dos direitos dos presos, essa medida reduziria em muito a eficácia social dos direitos fundamentais direcionados a esse grupo, agravando-se o estado de coisas inconstitucional (ADPF 347) e inconvencional (LEGALE, ARAúJO, 2016) que se apresenta quando observamos nossa realidade penal; logo, aplicável aqui o princípio da vedação ao retrocesso social(BARROSO, 2001, p. 158): ao reduzir a abrangência etária do ECA e reduzir drasticamente a eficácia dos direitos fundamentais de jovens entre 16 e 18 anos, a Emenda Constitucional dá enormes passos para trás, em direção ao obscurantismo e ao punitivismo, trazendo nada além de dor e medo a um grupo já historicamente vulnerável.

A percepção da maioridade penal como cláusula pétrea é compartilhada por grande parte da doutrina e da jurisprudência brasileiraxviii. Até porque, apesar de oposições quanto ao reconhecimento de direitos e garantias fundamentais além daqueles previstos no artigo $5^{\circ}$ do texto constitucional, vem prevalecendo o entendimento de que as cláusulas pétreas insculpidas no art. 60, $4^{\circ}$, IV, da CF alcançam um conjunto mais amplo de direitos e garantias constitucionais no texto da Carta Magna.

Apesar das mais de 100 emendas à Constituição de 1988 ao longo dos seus 30 anos - nem todas facilmente percebidas como constitucionais, e muitas extremamente criticáveis, como a recente EC 95/2016 (a conhecida "PEC do teto de gastos") -, vale notar que, como a CRFB brasileira é analítica e muito ampla, seu núcleo essencial é mais restrito, englobando uma parcela mais qualificada de direitos e garantias fundamentais, dentre as quais faz parte, por exemplo, a maioridade penal.

Mudar a maioridade penal como estabelecida pelo Brasil em 1988 é romper, simbolicamente, com tudo o que a CRFB representa: seu projeto de país, de sociedade, os valores que ela encarna e o que ela objetivou para o futuro, em particular, para a juventude pobre e negra de nosso país.

\section{A maioridade penal no Brasil pós-democrático}

Como apontado acima, a teorização constitucional das cláusulas pétreas levou em consideração, essencialmente, a tensão entre duas forças potencialmente em conflito: democracia e constitucionalismo.

Refletir sobre a possibilidade de redução da maioridade penal no Brasil contemporâneo, nestes termos definidos, esbarra em dois problemas no que concerne às cláusulas pétreas: primeiro, porque democracia e constitucionalismo são conceitos que guardam maior ou menor grau de correspondência à realidade empírica subjacente; segundo, porque, se o Brasil busca construir e afirmar seu constitucionalismo desde 1988, não se pode dizer o mesmo em relação à sua democracia, principalmente nos dias atuais.

Por essas razões, a problemática da maioridade penal no Brasil deve ser analisada não em vista de uma teorização ideal e abstrata, mas em função da realidade, e, por isso, a tensão parece existir, hoje, entre constitucionalismo, democracia e pós-democracia.

É suficientemente perceptível, em uma perspectiva global, que o mundo assiste a uma radical guinada à direita do espectro político: candidatos, governos, e parlamentos ao redor do mundo ocidental assumem feições cada vez mais conservadoras e reacionárias. Deixando de lado particularidades regionais (como, por exemplo, maior ou menor inclinação ao nacionalismo e à xenofobia, maior ou menor intervenção estatal na economia), fato é que projetos políticos que se assumem como "progressistas" ou "de esquerda" tem perdido espaço e poder em favor da ascensão de novas forças políticas centrais ou "de direita", e isso tanto nos países do Norte como do Sul Global. 
Um elo que liga este fenômeno comum entre as duas regiões do mundo é o neoliberalismo, cuja racionalidade econométrica e tecnocrática se espraia por todas as dimensões do corpo social, e, assim, entra em conflito com ideais e projetos políticos mais substancialmente democráticos, o que assume contornos e dimensões particulares na América Latina.

Em nossa região, o esgotamento dos projetos políticos de esquerda "pós-neoliberais" verificado a partir do final dos anos 2000 e início dos anos 2010 (impeachment de Fernando Lugo, Paraguai; derrota de Rafael Correa, Equador; vitórias de direita na Colômbia; vitória de Macri na Argentina e impeachment de Dilma Roussef, para citar alguns exemplos) confirma o que vem sendo chamado de "fim de ciclo", isto é, o encerramento do ciclo de governos progressistas na região, em favor da ascensão de uma "nova direita", com projetos mais profundamente neoliberais, autoritários e conservadores (SVAMPA, 2017; SEGRERA, 2016).

Nesse contexto ${ }^{\mathrm{xix}}$, começam a ganhar força os estudos e análises do que veio a se chamar "pós-democracia"xx. Segundo Chantal Mouffe (2018), trata-se de um momento em que a tensão clássica entre liberalismo político e democracia popular desaparecem em prejuízo da última, ocasião em que os valores democráticos fundamentais, igualdade e soberania popular se esfacelam, reduzindo-se à eleições livres e a uma aparência de defesa dos direitos humanos - temperada pelos interesses do livre mercado. Para além dos efeitos imediatos de ruptura com os pactos de manutenção de direitos mínimos, a pós-democracia tem amortecido os espaços em que diferentes projetos da sociedade poderiam se confrontar, sem que se tenha deixado em falar em "democracia":

\begin{abstract}
"Certamente, ainda se fala em 'democracia', mas foi reduzida ao seu componente liberal e significa apenas a presença de eleições livres e a defesa dos direitos humanos. O que se tornou cada vez mais central é o liberalismo econômico, com sua defesa do livre mercado, e muitos aspectos do liberalismo político que foram relegados para o segundo lugar, se não simplesmente eliminados. É isso que quero dizer com "pós-democracia"xxi (MOUFFE, 2018, p. 16, tradução nossa)
\end{abstract}

O momento nos convoca a pensar que o neoliberalismo modificou as estruturas políticas do Estado, de modo que, formalmente, os pilares, normas e fundamentos democráticos seguem inalterados, mas seu conteúdo é esvaziado. Direitos e garantias fundamentais existiriam, e seriam respeitados, mas o poder adviria de outras fontes, como grandes corporações transnacionais, mercados, agências de risco, organizações internacionais e organismos tecnocráticos (SINTOMER, 2017). Como aponta Luciana Ballestrin,

A conjuntura pós-democrática atual pode ser caracterizada a partir de uma série de eventos que sugerem a escalada global de a)um recuo democrático no seu sentido hegemônico e formal, possibilitado por dentro das próprias instituições democráticas; b) a ascensão de discursos abertamente autoritários, antidemocráticos e antihumanistas, com apelo e adesão popular/populista; c) a crescente colonização da esfera econômica internacional sobre a vida política nacional; d) o espraiamento da razão neoliberal para todas as esferas da vida pessoal e coletiva, inclusive política; e)o esvaziamento da política e da democracia (2017, p. 14).

O problema desta concepção é que, por mais que ela possa ser adequada ao Norte, definitivamente não o é em relação ao Sul Global (e em especial na América Latina e Brasil), 
onde afirmar a efetividade de direitos e garantias fundamentais, e seu respeito e promoção pelo Estado é, no mínimo, problemático (CASARA, p. 24-25).

Para Ballestrin, no Sul Global, a instrumentalização concreta da pós-democracia, em termos de técnica de poder, não é de forma biopolítica, mas, sim, necropolíticaxxii, tendo em vista a vulnerabilidade de suas economias dependentes, a realidade de suas desigualdades estruturais e a abrangência do fenômeno da violência (2017, p. 16).

A pauta da redução da maioridade penal nos informa que a pós-democracia brasileira terá, certamente, a juventude pobre e negra como um de seus primeiros principais alvos, porque sua punição penal simbolizaria uma autoafirmação política de poder e confiança no Estado, supostamente "combatendo a impunidade" e porque são mais vulneráveis e desprovidos de proteção jurídica e política ao arbítrio do poder, logo, alvos fáceis.

Em uma amarga síntese, a pós-democracia brasileira inverte a regra constitucional do art. 227: de uma absoluta prioridade em direitos, os adolescentes autores de atos infracionais passam a ter uma prioridade absoluta em violações, abuso e desrespeito. 0 status de cláusula pétrea da ordem não constrange a atual soberania, que, pelo contrário, se apoia na manutenção formal da Constituição para sustentar-se em falácia democrática. A propagação, porém, deste viés e a discussão do tema junto à sociedade civil pode tensionar esta base de sustentação. Se prevaleceu, ao que parece, a base democrática do presidente pela palavra vazia da vigência constitucional, a revelação do conteúdo esvaziante da mesma e do caráter cada vez mais soberano dos totalitarismos vigentes desperta atenção e convoca a reclamação por novos conteúdos de democracia em tempos de crise. É esse, talvez, o principal papel das discussões, ainda resistentes, nas interfaces da filosofia com o direito.

\section{Considerações finais}

O trabalho buscou apresentar panoramas possíveis para a maioridade penal no Brasil diante do contexto atual de autoritarismo e escatologia da violência, ainda que mantido o suposto estado constitucional. A apresentação teórica do estado de exceção auxilia na análise conjuntural, do horizonte de reedição e, até, de aprovação da pauta da redução,contingenciada na emergência das exceções próprias ao momento de verdadeira figuração das bases do que já se chamou "democracia" e "direitos fundamentais".

A ordem proclamada, embora ainda não tenha anunciado explicitamente as novas contingências nas periferias da sociedade brasileira, tem posto à prova as históricas estratégias de extermínio em território marginal com variações ainda em rascunho dos Estados pós-democráticos. Nesse sentido, projetos que escandalizam quanto aos retrocessos em direito que significam, como é o caso da redução da maioridade penal em um Estado supostamente constitucional, deixam a claro aquilo que Aganbem já sinalizava: é urgente repensar "Estado" e, mais ainda, "direito" (2004, p. 131).

A descrença nas instituições formais e no estado de coisas político, porém, não deve silenciar as possíveis expressões de resistência. Como pontua Foucault, "que lá onde há poder, há resistência e, no entanto (ou melhor, por isso mesmo) esta nunca se encontra em posição de exterioridade em relação ao poder" (FOUCAULT, 1999, p. 91). Assim, é preciso insurgência para se contrapor às relações de poder constituintes em temas sensíveis a direitos como o que tratamos neste artigo.

Em um contexto de exceção pós-democrática, de derrubada das conquistas de 1988 e de esgotamento do maquinário supostamente democrático que mantinha a organização política brasileira, garantias e direitos fundamentais - que precisam, sem dúvida, ser revistos - ainda são instrumentos possíveis para o enfrentamento da disputa em torno de assuntos e 
agendas primordiais. Começar esta empreitada a partir de seus titulares prioritários, a juventude, apresenta-se como tática de resistência - intelectual, acadêmica, política e jurídica - que visa a um horizonte mais amplo de reformulação daquilo que é base material de um estado cujo epicentro sejam as garantias de minorias.

(Recebido para publicação em março de 2019)

(Reapresentado em abril de 2019)

(Aprovado para publicação em abril de 2019)

\section{Cite este artigo}

FERNANDES, Luciana; FERRAZ, Hamilton, 2019. Estado de exceção e maioridade penal no Brasil pós- democrático.

Revista Estudos Políticos: a publicação semestral do Laboratório de Estudos Hum(e)anos (UFF). Rio de Janeiro, Vol.10 | N.1, pp. 51-72, maio de 2019.

\section{Notas}

1. Homem enquanto espécie faz com que a população possa se passar como um fenômeno da natureza, fundamental para a bio-política: 'A população aparece, portanto, nessa espécie de espessura em relação ao voluntarismo legalista do soberano, como um fenômeno de natureza(...)" (FOUCAULT, 2008, p. 93)

2. Sobre a noção de populações: "é a partir da constituição da população como correlato das técnicas de poder que pudemos ver abrir-se toda uma série de domínios de objetos para saberes possíveis. $\mathrm{E}$, em contrapartida, foi porque esses saberes recortavam sem cessar novos objetos que a população pôde se constituir (...)" (idem, p. 103).

3. Foucault esclarece que "as mudanças econômicas do século XVIII tornaram necessário fazer circular os efeitos do poder, por canais cada vez mais sutis, chegando até aos próprios indivíduos, seus corpos, seus gestos, cada um de seus desempenhos cotidianos." (FOUCAULT, 2016, p. 326)

4. Para uma crítica ao decisionismo schmittiano a partir de Antonio Negri e Spinoza, conferir, por todos, GUIMARAENS, 2016.

5. Uma primeira linha de contribuições surge de estudos críticos que se dedicam à colonialidade do poder e à crítica ao racismo (QUIJANO, 2009; 2010; SEGATO, 2007; PIRES, 2018).

6. Sem a pretensão de esgotar o tema, sustenta-se que, na periferia, a ocupação colonial e o escravismo representaram os primeiros casos de estados de 
exceção permanente, antecedendo em muito os campos de extermínio nazistas descritos por Agamben (SOUZA, 2015, p. 128-129; NASCIMENTO, 2016).

7. Sobre cláusulas pétreas e direitos fundamentais, conferir BRANDÃO, 2007; SARLET, 2015, p. 402 e ss.

8. Trata-se de um argumento de identidade constitucional, mas que, aqui é adotado com ressalvas. Uma Constituição não pode ser lida como absolutamente inalterável, e sua identidade pode ser construída e reconstruída pelas gerações futuras ao longo da tensão permanente entre democracia e constitucionalismo. Nesse sentido, conferir, por todos, SOUZA NETO, SARMENTO, 2012, p. 296.

9. PEC 04/2019. Disponível em < https://legis.senado.leg.br/sdleggetter/documento?dm $=7916543 \&$ ts $=1553282774532 \&$ disposition=inline $>$. Acesso em 26/06/2019. https://legis.senado.leg.br/sdleggetter/documento?dm $=4363543 \&$ ts $=1560887470273 \&$ disposition=inline https://legis.senado.leg.br/sdleggetter/documento?dm $=3668102 \& \mathrm{ts}=1556837882216 \&$ disposition=inlinePesquisa Datafolha (2018) aponta que $84 \%$ aprova a redução, pesquisa Vertude (entregue à Câmara) indicou $83,9 \%$ e pesquisa DataSenado (2015) verificou uma maioria favorável à redução de $85 \%$.

10. Nesse sentido, vide posicionamento do Instituto Brasileiro de Ciências Criminais (IBCCRIM) rechaçando a proposta (http://www.ibccrim.org.br/docs/PEC_171_93.pdf) e, no mesmo sentido, também o Instituto Carioca de Criminologia (http://www.anf.org.br/18283); por fim, a UNICEF se levantou em repúdio à redução (http://www.unicef.org/brazil/pt/media 29163.html http://agenciabrasil.ebc.com.br/politica/noticia/201811/moro-converge-com-bolsonaro-sobre-maioridadepenal-e-posse-de-armas

11. Art. 228. São penalmente inimputáveis os menores de dezoito anos, sujeitos às normas da legislação especial.

12. 12. De forma mais aprofundada, conferir FERRAZ, 2015. Digno de nota que nosso patamar etário de 18 anos segue o mesmo desde a Lei 4.242/1921, que primeiro o fixou neste sentido.

13. Todos contam com resumos disponíveis no site do Núcleo Interamericano de Direitos Humanos da Faculdade Nacional de Direito (NIDH-FND) $<$ https://nidh.com.br/> . 
14. Consideram a inimputabilidade penal uma cláusula pétrea implícita DOTTI, 2003, p. 412-413; VERONESE, 2015, p. 93-95; ROSA, LOPES, 2011, p. 317-319; SPOSATO, 2011, p. 196-203; SHECAIRA, 2015, p. 141142; SARAIVA, 2010, p. 47; RODRIGUES, 2016, p. 225-226.

15. Convém esclarecer que não se pretende sugerir um marco cronológico para o início do momento pósdemocrático brasileiro, o que demandaria um trabalho de muito maior esforço e fôlego, sem prejuízo de outros objetos e metodologia. Inobstante a temática da "pós-democracia" ter adentrado nos debates brasileiros um tanto tardiamente, isso não parece exigir como decorrência lógica que se investigue ou se esclareça sobre seu "nascimento" no Brasil. Seja como for, sabe-se das inúmeras violações a direitos fundamentais ocorridas em governos passados, nos mais variados espectros políticos, e admite-se aqui a própria possibilidade, inclusive extrema, de que 0 próprio regime constitucional de 1988 tenha sido, em sua boa medida, "pós-democrático". Porém, a circunstância contemporânea brasileira de um Presidente da República cujo livro de cabeceira é a apologia de um dos mais atrozes torturadores do regime militar; um Governador de Estado que afirma sem pudores que sua política de segurança pública se baseia em "tiro na cabecinha" de suspeitos autores de infrações penais; e membros do Ministério Público e do Judiciário que se posicionam abertamente contra 0 que chamam de "bandidolatria"; em suma, a circunstância de atores institucionais, em aparente e formal regime de normalidade política, que menosprezam frontalmente direitos, sugere que, se ainda não se pode afirmar quando, exatamente, teve início a pós-democracia brasileira (dada as grandes fragilidades e contradições da democracia em sua história), ao menos este é um tema que, hoje, não pode deixar de ser levantado.

16. Termo que foi desenvolvido principalmente por Rancière (2014) e Crouch (2004), entre os anos 90 e 2000 , tendo em vista o contexto dos países centrais.

17. "To be sure, 'democracy' is still spoken of, but it has been reduced to its liberal component and it only signifies the presence of free elections and the defence of human rights. What has become increasingly central is economic liberalism with its defence of the free market and many aspects of political liberalism have been relegated to second 
place, if not simply eliminated. This is what I mean by 'post-democracy"'.

18. Embora se faça menção indireta ao conceito de Achilles Mbembe de "necropolítica" (sobre ele, MBEMBE, 2016), não se desconhece a noção de "tanatopolítica", de Agambem, e suas relações com o conceito foucaultiano de biopolítica (AGAMBEM, 2007). Não se pretende discutir neste trabalho as relações entre os dois conceitos, mas, apenas para fins de esclarecimento, a categoria da necropolítica é aqui lançada tendo em vista principalmente suas bases contextuais - no caso, o colonialismo. Já a "tanatopolítica" é um conceito que, em que pese sua importância, foi elaborado tendo em vista o contexto europeu e central do nazismo, razão pela qual preferiu-se não o empregar em relação ao problema proposto pelo presente trabalho.

\section{Referências bibliográficas}

AGAMBEN, Giorgio. Estado de exceção. Trad. de Iraci D. Poleti. São Paulo: Boitempo, 2004.

- Homo sacer: o poder soberano e a vida nua. Trad. de Henrique Burigo. 2a Reimp. Belo Horizonte: Editora UFMG, 2007.

BALLESTRIN, Luciana. Rumo à teoria pós-democrática?. 41 Encontro Anual da Anpocs, 2017.

BARATTA, Alessandro. Prefácio. In: BATISTA, Vera Malaguti. Difíceis Ganhos Fáceis. $1^{a}$ Reimpressão. Rio de Janeiro: Revan, 2013.

BARRETO, Tobias. Menores e loucos. Edição do Estado de Sergipe, 1926.

BARROSO, Luís Roberto. O direito constitucional e a efetividade de suas normas. $5^{a}$ Ed. Rio de Janeiro: Renovar, 2001.

BATISTA, Nilo. Punidos e mal pagos: violência, justiça, segurança pública e direitos humanos no Brasil de hoje. Rio de Janeiro: Revan, 1990.

BATISTA, Vera Malaguti. Difíceis ganhos fáceis. Drogas e juventude pobre no Rio de Janeiro. Rio de Janeiro: Instituto Carioca de Criminologia: Freitas Bastos, 1998.

BRANDÃO, Rodrigo. Direitos fundamentais, cláusulas pétreas e democracia: uma proposta de justificação e de aplicação do art. 60, §40, IV da CF/88. Revisa Eletrônica 
de Direito do Estado, n. 10, abril/maio/junho de 2007, Salvador, Bahia, p. 1-44.

BRASIL, CAMARA DOS DEPUTADOS. Pesquisa: $83,9 \%$ dos brasileiros são favoráveis à redução da maioridade penal. Disponível em https://www2.camara.leg.br/camaranoticias/noticias/DIRE ITO-E-JUSTICA/494131-PESQUISA-83,9-DOSBRASILEIROS-SAO-FAVORAVEIS-A-REDUCAO-DAMAIORIDADE-PENAL.html> Acesso em 26/06/2019.

CARVALHO, Salo de; FERNANDES, Eduardo Georjão e MAYER, Denise Both. Direitos da criança e do adolescente no Brasil: da doutrina da situação irregular à doutrina da proteção integral. In: CRAIDY, Carmem Maria et. al (orgs.). Processos educativos com adolescentes em conflito com a lei. Porto Alegre: Mediação, 2012, p. 1730.CARVALHO, Thiago Fabres de. O "direito penal do inimigo" e o "direito penal do homo sacer da baixada": exclusão e vitimação no campo penal brasileiro. Discursos Sediciosos: crime, direito e sociedade, Rio de Janeiro, v. 17, 19/20, p. 101-129, $1^{\circ}$ e $2^{\circ}$ semestres, 2012.

CASARA, Rubens. Estado pós-democrático: neoobscurantismo e gestão dos indesejáveis. Rio de Janeiro: Civilização Brasileira, 2017.

CASTRO, Edgardo. Introdução a Giorgio Agamben: uma arqueologia da potência. Trad. de Beatriz de Almeida Magalhães. $1^{\mathrm{a}}$ Ed., $2^{\mathrm{a}}$ Reimp. Belo Horizonte: Autêntica, 2016.

CROUCH, Colin. Post-democracy. Polity Press: Cambridge, Reino Unido, 2004.

DARDOT, Pierre; LAVAL, Christian. A nova razão do mundo: ensaio sobre a sociedade neoliberal. Trad. de Mariana Echalar. São Paulo: Boitempo, 2016.

DATAFOLHA. Maioria quer redução da maioridade penal e é contra posse de armas. Disponível em < http://datafolha.folha.uol.com.br/opiniaopublica/2019/01/ 1985980-maioria-quer-reducao-da-maioridade-penal-e-econtra-posse-de-armas.shtml>. Acesso em 26/06/2019.

DEL PRIORE, Mary. História das crianças no Brasil. São Paulo: Contexto, 1991. História das crianças no brasil. 7a Ed. $1^{a}$ reimpressão. São Paulo: Contexto, 2013.

DOTTI, René Ariel. Curso de Direito Penal: parte geral. Rio de Janeiro: Forense, 2003.

FERRAZ, Hamilton Gonçalves. Você conhece a história da idade penal no Brasil? Disponível em: <http://justificando.com/2015/03/21/voce-conhece-a- 
historia-da-idade-penal-no-brasil/>. Acesso em 16 nov. 2018.

FOUCAULT, Michel. História da Sexualidade I: a vontade de saber. Trad. de. Maria Thereza da Costa Albuquerque e J.A. Guilhon Albuquerque. 13a Ed. Rio de Janeiro: Graal, 1999.

- Segurança, Território, População. Curso no

Collège de France (1977-1978). São Paulo: Martins Fontes, 2008.

FOUCAULT, Michel. Microfísica do Poder. Rio de Janeiro: Paz e Terra, 2016.

GUIMARAENS, Francisco de. O poder constituinte segundo Antonio Negri: um conceito marxita e spinozist. Direito e práxis, Rio de Janeiro, vol. 07, N. 4, 2016, p. 135-168.

LEGALE, Siddharta; ARAÚJO, David Pereira de. O Estado de Coisas Inconvencional: trazendo a Corte Interamericana de Direitos Humanos para o debate sobre o sistema prisional brasileiro. Revista Publicum, Rio de Janeiro, Número 3, 2016, p. 67-82.

MBEMBE, Achille. Necropolítica. Arte \& Ensaios, Revista do PPGAV/EBA/UFRJ, n. 32, dez. 2016, p. 123-151.

MORAES, Evaristo de. Criminalidade na infância e na adolescência. $2^{\mathrm{a}}$ Ed, modificada e ampliada. Rio de Janeiro: Livraria Francisco Alves, 1927.

MOUFFE, Chantal. For a left populism. Verso Books, 2018.

NASCIMENTO, Daniel Arruda. A exceção colonial brasileira: o campo biopolítico e a senzala. Cadernos de Ética e Filosofia Política, São Paulo, n. 28, 2016, p. 19-35.

OLIVEIRA, Siro Darlan de; ROMÃO, Luis Fernando de França. A história da criança por seu conselho de direitos. Rio de Janeiro: Revan, 2015.

PEDRINHA, Roberta Duboc. Breves apontamentos acerca da política criminal e da instituição policial na contemporaneidade. Passagens. Revista Internacional de História Política e Cultura Jurídica, Rio de Janeiro: vol. 3, no.2, maio-agosto 2011, p. 167- 186.

PIRES, Thula Rafaela de Oliveira. (2018). Criminologia crítica e pacto narcísico: por uma crítica criminológica apreensível em pretuguês. Revista brasileira de ciências criminais, n. 135 , p. 541-562.

QUIJANO, Aníbal. Colonialidade do poder e classificação social. In: SANTOS, Boaventura de Sousa \& MENESES, 
Maria Paula (Orgs). Epistemologias do Sul. São Paulo: Cortez, 2010.

Colonialidad del Poder y Descolonialidad del Poder. Conferencia dictada en el XXVII Congreso de la Asociación Latinoamericana de Sociología, Buenos Aires, pp. 1-15, 2009.

RANCIÈRE, Jacques. O ódio à democracia. São Paulo: Boitempo, 2014.

RIZZINI, Irma., O Surgimento das instituições especializadas na internação de menores delinquentes. In. ZAMORA, Maria Helena (org.). Para além das grades: elementos para a transformação do sistema socioeducativo. Rio de Janeiro: Ed. PUC-Rio, 2005.

; PILOTTI, Francisco. A arte de governar crianças: a história das políticas sociais, da legislação e da assistência à infância no Brasil. $3^{a}$ Ed. São Paulo: Cortez, 2011.

RODRIGUES, Ellen Cristina Carmo. A Justiça Juvenil no Brasil e a responsabilidade penal do adolescente: rupturas, permanências e possibilidades. Tese de Doutorado. Universidade do Estado do Rio de Janeiro, Programa de Pós-Graduação em Direito, 2016.

ROSA, Alexandre Morais da.; LOPES, Ana Christina Brito. Introdução crítica ao ato infracional. Princípios e Garantias Constitucionais. 2a ed. Rio de Janeiro: Lumen Juris, 2011.

SARAIVA, JOÃO Batista Costa. Compêndio de direito penal juvenil: adolescente e ato infracional. $4^{a}$ ed. rev. e atual. Porto Alegre: Livraria do Advogado Editoria, 2010.

SARLET, Ingo Wolfgang. A eficácia dos direitos fundamentais: uma teoria geral dos direitos fundamentais na perspectiva constitucional. $12^{\mathrm{a}} \mathrm{Ed}$. rev., atual. e ampl. Porto Alegre: Livraria do Advogado, 2015.

SEGATO, Rita Laura. El color de la cárcel en América Latina: apuntes sobre la colonialidad de la justicia en un continente en desconstrucción. Nueva sociedad, v. 208, p. 142-162, 2007.

SEGRERA, Francisco López. América Latina: crisis del posneoliberalismo y ascenso de la nueva derecha. Ciudad Autónoma de Buenos Aires: CLACSO, 2016.

SENADO NOTÍCIAS. Pesquisa do DataSenado aponta que maioria dos entrevistados quer redução da maioridade penal. Disponível em < https://www12.senado.leg.br/noticias/materias/2015/07/1 6/pesquisa-do-datasenado-aponta-que-maioria-dos- 
entrevistados-quer-reducao-da-maioridade-penal> Acesso em 16 nov. 2018.

SHECAIRA, Sérgio Salomão. Sistema de garantias e o direito penal juvenil. $2^{a}$ ed. rev. e atual. São Paulo: Editora Revista dos Tribunais, 2015.

SINTOMER, Yves. ¿Condenados a la posdemocracia? Disponível em: <http://nuso.org/articulo/condenados-laposdemocracia/>. Acesso em 16 nov. 2018.

SOUZA, José Elielton de Souza; OLIVEIRA, Maria do Socorro Catarina de Sousa. Considerações sobre o conceito de "Estado de Exceção" em Giorgio Agamben. Intuitio, Porto Alegre, v. 9, n. 1, Julho 2016, p. 131-147.

SOUZA, Jessé de. Prefácio. In: VALIM, Rafael. Estado de exceção: a forma jurídica do neoliberalismo. São Paulo: Contracorrente, 2017.

SOUZA, Taiguara Libano Soares e. A Era do Grande Encarceramento: Tortura e Superlotação Prisional no Rio de Janeiro. Tese de Doutorado. Pontifícia Universidade Católica do Rio de Janeiro (PUC-Rio), Programa de PósGraduação em Direito, 2015.

SOUZA NETO, Cláudio Pereira de e SARMENTO, Daniel. Direito constitucional: teoria, história e métodos de trabalho. Belo Horizonte: Fórum, 2012.

SPOSATO, Karyna Batista. O Direito Penal Juvenil. São Paulo: Editora Revista dos Tribunais, 2006.

- Elementos para uma teoria da responsabilidade penal de adolescentes. Tese de Doutorado. Universidade Federal da Bahia, Programa de Pós Graduação em Direito, 2011.

SVAMPA, Maristella. Populismos latinoamericanos en el fin del ciclo progresista. Disponível em: $<$ http://www.sinpermiso.info/textos/populismoslatinoamericanos-en-el-fin-del-ciclo-progresista>. Acesso em 16 nov. 2018.

VALENTE, Júlia. Upps: governo militarizado e a ideia de pacificação. Rio de Janeiro: Revan, 2016.

VALIM, Rafael. Estado de exceção: a forma jurídica do neoliberalismo. São Paulo: Contracorrente, 2017.

VERONESE, Josiane Rose Petry. Direito Penal Juvenil e responsabilização estatutária: elementos aproximativos e/ou distanciadores? : o que diz a Lei Sinase: a inimputabilidade penal em debate. Rio de Janeiro: Lumen Juris, 2015. 
ESTADO DE EXCEÇÃO E

REVISTA ESTUDOS POLÍTICOS Vol. 10 | N.1 ISSN 2177-2851

MAIORIDADE PENAL NO BRASIL PÓS- DEMOCRÁTICO

Luciana Fernandes e Hamilton Ferraz 